$04,11,13$

\title{
Образование тонких пленок и малоразмерных монокристаллов из газовой фазы на поверхностях ионных кристаллов в условиях нагрева и электрического поля
}

\author{
(С) Л.Г. Карыев, В.А. Федоров, А.В. Чиванов \\ Тамбовский государственный университет им. Г.Р. Державина, \\ Тамбов, Россия \\ E-mail: karyev@list.ru
}

Поступила в Редакцию 16 июля 2019 г.

В окончательной редакции 16 июля 2019 г.

Принята к публикации 25 июля 2019 г.

\begin{abstract}
Исследовано поведение поверхностей ионных кристаллов различной кристаллографической ориентации и поверхностей скола в условиях нагрева и электрического поля. Изменения на поверхностях образцов проявляются в виде образования вязкой жидкости или малоразмерных монокристаллов. На поверхностях кристаллов образуется заряд, как результат обеднения или насыщения приповерхностных слоев кристалла положительными ионами, что приводит к стехиометрическому изменению вещества кристалла. Монокристаллы образуются из ионного газа, появление которого инициировано сублимацией матричных ионов с поверхности скола.
\end{abstract}

Ключевые слова: ионный кристалл, поверхность, нагрев, электрический ток, пленка.

DOI: $10.21883 /$ FTT.2019.12.48553.27ks

В настоящее время рождаются и развиваются новые области науки и техники, базирующиеся на широком использовании уникальных свойств ионных кристаллов, которые широко используются в дозиметрии, в оптических и медицинских приборах, компьютерных технологиях. Проблемы роста кристаллов в различных условиях, образование пленок на них представляют не только собственный интерес. Поверхности ионных кристаллов, покрытые пленками из различных материалов, имеют большое практическое применение. В связи с этим проведены исследования образования тонких пленок на поверхности ионных кристаллов и роста микрокристаллов в условиях нагрева и электрического поля.

В первом случае, во всех опытах нагреву и одновременному воздействию поля подвергались кристаллы, ограненные нетравлеными поверхностями $\{100\}-\mathrm{NaCl}$, $\mathrm{KCl}, \mathrm{CaCO}_{3}$ и $\{111\},\{100\},\{350\},\{110\}-\mathrm{LiF}$ (coотношение ретикулярных плотностей для исследуемых плоскостей 1.15:1:0.86:0.71, соответственно). Размеры образцов $20 \times 8 \times 3 \mathrm{~mm}$. Содержание примесей для $\mathrm{LiF}$ по $\mathrm{Ca}^{2+}, \mathrm{Mg}^{2+}, \mathrm{Ba}^{2+}$ в сумме не превышало $\sim 10^{-3} \mathrm{wt} . \%$, для $\mathrm{KCl}$ и $\mathrm{NaCl}-10^{-2}$ wt.\% по $\mathrm{Mn}^{2+}$ и $\mathrm{Fe}^{3+}$, соответственно. $\mathrm{CaCO}_{3}$ - природные кристаллы.

На рис. 1 изображена схема экспериментальной установки. Между плоскими электродами (2) размещался образец (1). Одна грань кристалла контактировала с электродом.

Между свободной поверхностью образца и вторым электродом оставался воздушный зазор $d \sim 0.1 \mathrm{~mm}$, который регулировался с помощью изолированных подвесов (3). Размеры электродов не превышали размеров кристалла. Вся установка монтировалась на асбоцементной основе с использованием изоляторов из электротех- нической керамики и размещалась в печи (4). Электроды и все токоподводящие конструкции, находящиеся в печи, изготавливались из нихрома.

От источника тока (5) на электроды подавалось стабилизированное постоянное напряжение $U_{0}=400 \mathrm{~V}$, как положительной полярности - кристалл соединен с положительным полюсом источника тока, так и отрицательной - кристалл соединен с отрицательным полюсом источника тока. Электрическое напряжение на образце и печь включали одновременно. Величина электростатической индукции в межэлектродном пространстве не превышала $D=34.5 \cdot 10^{-6} \mathrm{~K} 1 / \mathrm{m}^{2}$. Плотность тока достигала значений $j \approx 0.8-1.3 \mathrm{~A} / \mathrm{m}^{2}$. Цифрами $6,7,8$ обозначены - микроаперметр, вольтметр, самопишущий прибор соответственно.

Опыты проводились в температурном интервале $293-1073$ К. Скорость нагрева составляла $\sim 200 \mathrm{~K} / \mathrm{h}$.

После нагрева до заданной температуры (при положительной полярности) и проведения замеров, электрическое напряжение на образце выключалось, и кри-

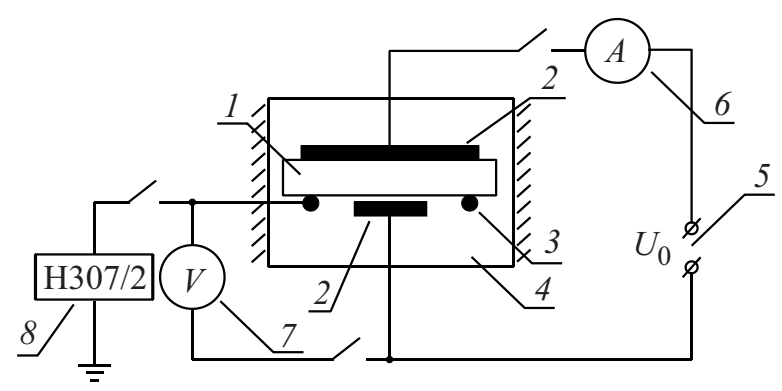

Рис. 1. Схема экспериментальной установки. 
$a$

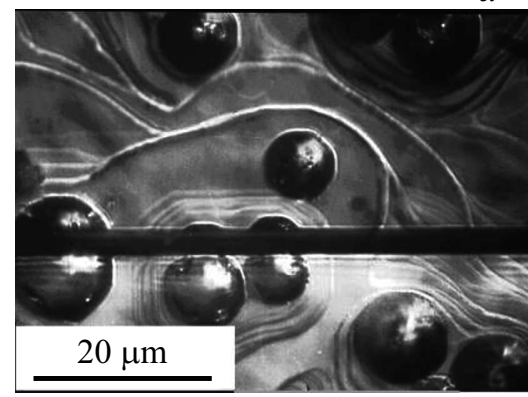

$d$

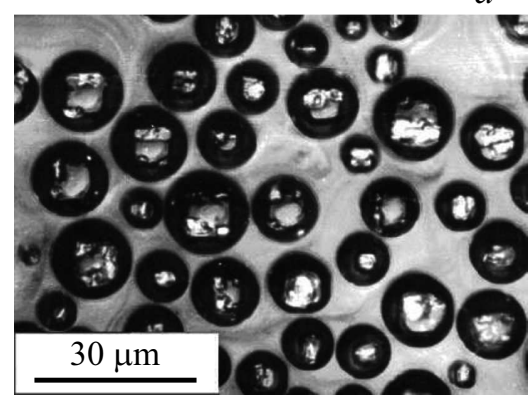

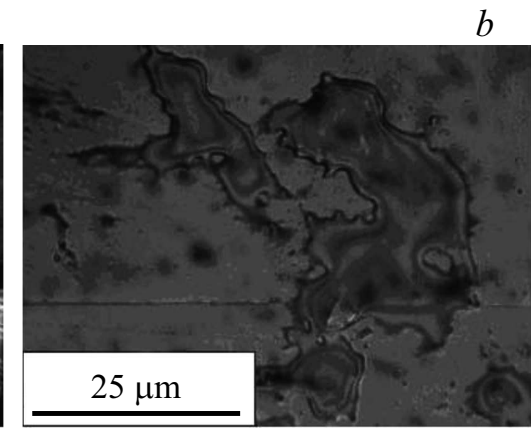

$e$

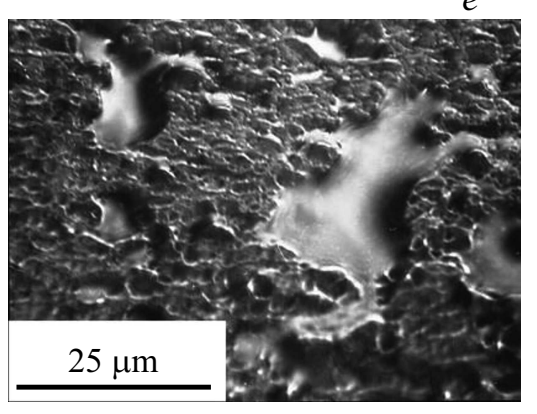

$b$
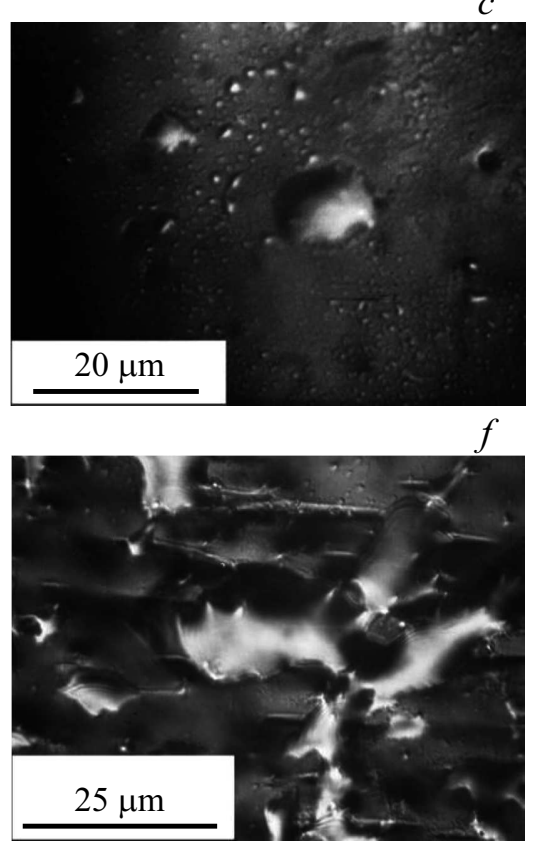

Рис. 2. Новая фаза на поверхности ионных кристаллов: $a$ ) в виде „капель“ желеобразной консистенции на поверхности $\{100\}$ КСl; b) в виде вязкой жидкости на поверхности $\left.\{100\} \mathrm{CaCO}_{3} ; c, d, e, f\right)$ новообразования на поверхностях $\{111\},\{100\},\{350\}$ и $\{110\}$ кристаллов $\mathrm{LiF}$ соответственно.

сталл остывал до комнатной температуры со скоростью $\sim 50 \mathrm{~K} / \mathrm{h}$, за исключением некоторых опытов, когда напряжение на образце не выключалось при его остывании, а полярность, при этом, изменяли на противоположную.

Отмечено, что на свободных поверхностях $\{100\}$ образцов из кристаллов $\mathrm{NaCl}, \mathrm{KCl}$ и $\mathrm{CaCO}_{3}$, а также на поверхностях $\{100\},\{350\},\{110\},\{111\}-$ $\mathrm{LiF}$ обнаружены изменения в виде каплеобразных островков как правильной, так и неправильной формы (рис. 2). Первоначально изменения появлялись на участках поверхности, содержащих неоднородности, такие как царапины, ступеньки скола и т.д., затем их появление наблюдалось на всем участке поверхности, подверженном воздействию поля. Области поверхности кристалла, выходящие за пределы электродов, не претерпевали видимых изменений. Новообразования имеют характерные размеры 3-300 $\mu \mathrm{m}$. При нагреве в отсутствие поля изменений этого типа не наблюдали. Новообразования на поверхности $\{100\}$ желеобразной консистенции, на остальных поверхностях и на поверхности $\{100\}$ кальцита - представляют собой вязкую жидкость смачивающую поверхность кристалла (рис. 2).

На поверхности $\{110\}$ кристаллов фтористого лития новообразования с размерами $1-3 \mu \mathrm{m}$ наблюдались при плотности тока $j \sim 0.015 \mathrm{~A} / \mathrm{m}^{2}$; с размерами $3-30 \mu \mathrm{m}-$ при плотности тока $j \sim 0.2 \mathrm{~A} / \mathrm{m}^{2}$; с размерами $30-300 \mu \mathrm{m}-j \sim 0.5 \mathrm{~A} / \mathrm{m}^{2}$. При плотности тока $j>0.5 \mathrm{~A} / \mathrm{m}^{2}$ наблюдались следующие варианты дальнейшего развития. Например, на поверхности $\{100\}$ в некоторых опытах сфероидальные образования имели размеры $1-3 \mu \mathrm{m}$, а вся поверхность кристалла (подвергнутая воздействию поля) между ними была покрыта тонким слоем $(\sim 1 \mu \mathrm{m})$ вязкой жидкости, в других случаях - наблюдалось слияние крупных „капель“ между собой. На поверхностях $\{350\},\{110\}$ и $\{111\}$ новообразования объединяются в крупные участки неопределенной формы или вся поверхность покрывается слоем вязкой жидкости.

На поверхностях $\{100\}$ всех исследуемых образцов появление новообразований сопровождается образованием под ними лунок, имеющих определенную кристаллографическую огранку. Поверхности лунок являются поверхностями раздела между кристаллом и желеобразным веществом.

В случае охлаждения кристаллов при полярности противоположной полярности нагрева и равенстве проходящих зарядов „капли“ исчезают.

Масс-спектрографические исследования показывают, что вещество новообразований по качественному составу отличается от матричной лишь присутствием ионов газовой среды.

Химический состав „капель“ одинаков с матрицей, а морфологическое отличие поверхностей после обработки может быть связано с изменением стехиометрического состава.

Исследование обработанных образцов методом рентгеноструктурного анализа показало наличие структурных изменений на поверхностях, подвергшихся обработке. Рентгенограммы снимались непосредственно с вещества „капель“. Диаметр рентгеновского пучка составлял $\sim 4 \mu \mathrm{m}$. В веществе новообразований в результате тер- 

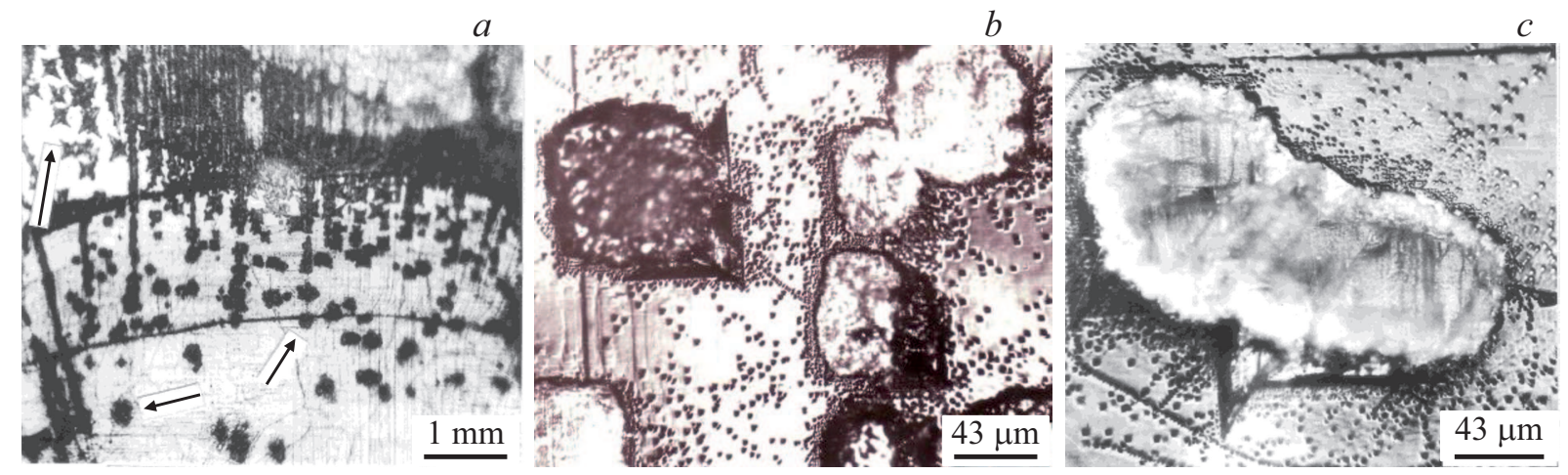

Рис. 3. Монокристаллические наросты на положительно заряженной поверхности искусственно введенной трещины скола: $a)$ - общий вид в области вершины трещины наросты крестовидной формы по мере удаления от вершины становятся округлой формы $(b, c) ; \mathrm{LiF}$.

моэлектрического воздействия происходит аморфизация, а в переходной зоне „капля“-кристалл еще сохраняется дальний порядок.

У всех образцов отмечено смещение кристаллических рефлексов от их положений в идеальном кристалле. Положение рефлексов позволяет оценить межплоскостное расстояние (межатомный параметр) по методу Вульфа-Брэгга с использованием автоматизированной системы расчета. Так, для LiF межатомное расстояние $d=2.015 \AA$, тогда как в приповерхностных областях для обработанных образцов $\mathrm{LiF}$ межатомное расстояние в случаях положительно и отрицательно заряженных поверхностей составляет $d=2.065 \AA$ и $d=2.072 \AA$ соответственно. Аналогичные результаты получены для кристаллов $\mathrm{NaCl}$ и $\mathrm{KCl}$.

Образование новой фазы на поверхностях ионных кристаллов обусловлено миграцией ионов в интервале температур, соответствующих собственной проводимости. Для обеих полярностей имеет место примесная и преобладающая катионная проводимость, анионная проводимость становится заметной лишь в области высоких температур [1]. На поверхностях кристаллов образуется заряд, как результат обеднения или насыщения приповерхностных слоев кристалла положительными ионами. При обеднении поверхности положительными ионами возможно ее разрушение за счет сил кулоновского взаимодействия.

Заметный вклад в образование поверхностного заряда также вносит различная скорость сублимации компонент матрицы, вызванная различным давлением насыщенных паров составляющих кристалл элементов при температурах близких к температуре плавления. Таким образом, присутствие нескомпенсированного заряда на поверхностях ионных кристаллов приводит к изменению стехиометрического соотношения ионов по отношению к стехиометрии матрицы.

Изменение параметра решетки матричного кристалла на границе раздела с новой фазой объясняется 1) повышением концентрации в междоузлиях ионов $\mathrm{Li}^{+}$на положительно заряженной поверхности и
2) обеднением ионами лития отрицательно заряженной поверхности. Новая фаза, имея тот же компонентный состав, что и кристалл, но отличаясь стехиометрическим соотношением компонентов, приобретает новые свойства. Образование новой фазы начинается при температуре $T_{k}$ - температуре перехода от примесной проводимости к собственной. Для исследованных кристаллов это температуры: $\mathrm{LiF} \sim 850 \mathrm{~K}, \mathrm{KCl} \sim 820 \mathrm{~K}, \mathrm{NaCl} \sim 850 \mathrm{~K}$, $\mathrm{CaCO}_{3} \sim 900 \mathrm{~K}$. Как показывает эксперимент эти температуры зависят от ретикулярной плотности исследуемых поверхностей: для поверхности $\{111\} \mathrm{LiF} T_{k}$ составляет $\sim 925 \mathrm{~K}$, для $\{100\} \sim 850 \mathrm{~K}$, для $\{350\} \sim 950 \mathrm{~K}$ и для $\{110\} \sim 975 \mathrm{~K}$.

Во втором случае, теплоэлектрическому воздействию подвергали трещину скола в кристаллах фтористого лития и хлористого натрия. Оба электрода, в этом случае, контактировали с гранями образца параллельными полости трещины. Опыты проводили в температурном интервале $293-893 \mathrm{~K}$ в воздушной среде и в вакууме $(\sim 0.01 \mathrm{~Pa})$. Плотность ионного тока достигала $\sim 27 \mathrm{~A} / \mathrm{m}^{2}$. Расстояние между поверхностями трещины составляло $\sim 5 \cdot 10^{-3}-10^{-1} \mathrm{~mm}$. Напряженность электрического поля между поверхностями составляла $1.6 \cdot 10^{6} \leq E_{0} \leq 1.3 \cdot 10^{7} \mathrm{~V} / \mathrm{m}$.

В температурном интервале собственной проводимости $(T>823 \mathrm{~K})$ наблюдали образование локальных монокристаллических наростов с размерами $4.4 \cdot 10^{-2}-3 \cdot 10^{-1} \mathrm{~mm}$. Формированию малоразмерных монокристаллов предшествовало появление дислокационных розеток. Во всех случаях кристаллы появлялись на положительно заряженных поверхностях (рис. 3).

Появление кристаллов в полости трещины обусловлено тем, что в части кристалла, находящейся на положительном электроде, перемещаются, в основном, в направлении внешнего электрического поля более подвижные ионы $\mathrm{Li}^{+}$и ионы примеси [1]. Ионы $\mathrm{F}^{-}$ практически неподвижны. Поверхность трещины при этом заряжается положительно без разрушения кристаллической решетки. Являясь энергетическим барьером для ионов $\mathrm{Li}^{+}$и примесей, поверхность препятствует 
эмиссии последних. Отрицательно заряженная поверхность трещины обедняется положительным зарядом, диффундирующим к отрицательному электроду. Межионные кулоновские силы и внешнее электрическое поле способствуют отрыву ионов $\mathrm{F}^{-}$(энергия сублимации последних уменьшается), что приводит к разрушению поверхностных слоев кристалла.

Возникающий анионный эмиссионный ток [3], бомбардируя положительно заряженную поверхность, приводит к деформационным сдвигам. Энергия ионов $\mathrm{F}^{-}$ при отмеченных напряженностях электрического поля достигает $\sim 70 \mathrm{eV}$. Пробой возникает в первую очередь в участках концентрации электрического поля (например, ступеньки скола).

Таким образом, наблюдаемые дислокационные розетки имеют различную физическую природу. На положительно заряженной поверхности несплошности розетки - результат микропластических сдвигов при бомбардировке ионами $\mathrm{F}^{-}$, а на отрицательно заряженной результат разрушения кристаллической решетки при электролизе.

Образование кристаллических наслоений связано с тем, что при бомбардировке ионами фтора положительно заряженной поверхности трещины в зонах пластических сдвигов имеет место механоэмиссия ионов лития [2]. В результате на положительно заряженной поверхности окруженной газом отрицательных ионов происходит рост малоразмерных кристаллов. Эксперименты по обнаружению и исследованию наростов в вакууме показали, что отличий в форме и кинетике развития наростов, полученных в обеих средах, не обнаружено. В вакууме наблюдали монокристаллические наслоения и в монокристаллах $\mathrm{NaCl}$.

Таким образом, показано, что при нагреве в электрическом поле 1) на поверхностях ионных кристаллах различной кристаллографической ориентации образуется тонкая пленка или желеобразное вещество в виде малоразмерных правильных сфероидальных образований, 2) на положительно заряженной поверхности скола находящейся в ионном газе образуются малоразмерные монокристаллы.

\section{Конфликт интересов}

Авторы заявляют об отсутствии конфликта интересов.

\section{Список литературы}

[1] А. Лидьярд. Ионная проводимость кристаллов. ИЛ, М. (1962). $222 \mathrm{c.}$

[2] М.И. Молоцкий. ДАН СССР 243, 1438 (1978).

[3] Л.Г. Карыев, В.А. Федоров, А.П. Занина. Изв. РАН. Сер. физ. 82, 1 (2018).

Редактор К.В. Емцев 